\title{
INFLUENCE OF A TRAINING MODEL FOR THE DEVELOPMENT OF THE SPEED-STRENGHT QUALITIES OF FEMAL STUDENTS FROM THE UNIVERSITY OF NATIONAL AND WORLD ECONOMY PRACTICING BASKETBALL
}

\author{
L. Kasabova* \\ Department of Physical Education and Sport, Business Faculty, University of National and \\ World Economy, Sofia, Bulgaria
}

\begin{abstract}
The changes that have occurred as a result of the application of a training model for the development of speed and strength qualities and the improvement of the basketball coordination of movement have been observed. The performance of the model was monitored in 38 students from the basketball study groups divided into two groups [EG] and [KG], after a preliminary test aimed at equalizing the groups at the beginning of the experiment. In the experimental group was applied and tested a model containing complexes of special exercises to develop bounce, speed and increase coordination of movements when performing technical - tactical techniques. At the beginning and end of the experiment, five indicators carrying information about the respective qualities were tested. The results are subjected to mathematical - statistical processing. The speed-strength readiness of the EG students improved in the application of the training model containing sets of exercises with short-term maximum strength loads with weights and multi-jumps.
\end{abstract}

Key words: learning process, optimization, efficiency, motor qualities, coordination.

\section{INTRODUCTION}

Sports education in higher education in the form of sports training is a pedagogical process of education, training, improvement of functional indicators of students in which constant pedagogical control is carried out and takes place in a certain hygienic regime in order to achieve high sports results, formation (1). Unfortunately, "the results of numerous studies dealing with the problems of physical education and sport in higher education show reduced physical activity and the existing disparities between physical development and motor skills in this age range." (2). Physical education and sports are of great importance for their proper physical development, for their health, as well as for the acquisition of the

\footnotetext{
*Correspondence to: Larissa Kasabova, University of National and World Economy, Sofia, Business Faculty, Department of Physical Education and Sport, December 8th Blvd. Bulgaria, Student's town, Sofia -1700, phone: (+359 2) 862 90 75, GSM: (+359) 894563333, e-mail: larissa.kasabova@gmail.com
}

necessary qualities and skills for their future professional realization as economists. Some authors establish professionally significant motor qualities for practicing the economic profession (3).

Today, the role and importance of the organized process of physical education and sports are becoming increasingly important. The problem of managing and optimizing this process in higher education is particularly significant (4). The vast majority of scientific research in the field of physical education is focused on trying out new sources and methods of influence, which would have a positive impact on the physical development in teenagers (5).

Basketball is one of the most practiced and desired sports in student circles. It is a dynamic game requiring players, a high level of speed strength and technical - tactical training. This level is formed in the long-term process of training of basketball players, which is constantly improved and updated in 


\section{KASABOVA L.}

accordance with modern trends in the game. The need for serious fitness training is becoming more and more necessary for basketball players nowadays.

In her research, Iren Peltekova found that "Speed is a basic conditioning quality for many sports, and basketball is one of them. His deficit could have a negative impact on both the player and the whole team (6). The same author also found "a significant difference in the strength of the arms, the upper part of the body and the explosive force, measured by a bounce from a place and with a maximum touch between the sexes, with a pronounced superiority in men. There is no gender difference in endurance data measured by a multi-jump test (7).

Long-term teaching and coaching practiceexperience show that poor performance in competitions is mainly a consequence of insufficient physical fitness. Sometimes in the training process of physical education and in competitions when fatigue occurs, elementary technical and tactical mistakes are made, typical for the initial stages of training. That is why the technical - tactical basketball training needs to be preceded and accompanied by serious physical training.

Basketball athletics, which meets the specific requirements of the game, imposes high demands on the functional training of players (8).

In this sense, the impact of training loads, the creation of model characteristics of physical and technical - tactical training, training methods and improvement, the sequence of use of training tools, periodization are scientific problems that are to be solved by sports educators from universities.

The sport of basketball places high demands on the development of motor skills. Some researchers have found that "the explosive power of the lower limbs is in a significant downward correlation with the $30 \mathrm{~m}$ and $50 \mathrm{~m}$ sprint (speed). This dependence confirms the statement that when working on the explosive force of the lower extremities, the speed and power capabilities are strongly influenced. It is a question of 'transforming power into speed (9).

The variability of the game situations requires, along with the mastery of the specific technical and tactical skills, a high level of special physical training. The influences between the individual motor qualities depend on the applied physical load and on the level of physical training. In sports disciplines with speed - power character in particular sports games (basketball, handball, futsal, football) with increasing qualification and age increases the correlation between the physical qualities that are leading for the chosen sport (10).

The efficiency of the applied methods, as well as the way of interpreting the obtained data plays a major role in the development of the speed-power qualities (11). The inclusion of shock-stress loads and concentrated volume for the main training aids will lead to the expansion of the adaptive capabilities of the athletes in the absorption of significant in volume and intensity loads, and will also optimize the ratio between the means for special physical and technical training (12).

\section{METHODS}

The aim of this study is to find an effective way to train female students in basketball groups, taking into account their level of physical fitness.

The tasks we set ourselves were:

1. To test the preparation model we have created.

2. To ascertain the obtained results and process them mathematically - statistically.

3 . To determine whether the training model is effective.

4. To make the appropriate conclusions and recommendations for the practice.

\section{Methods the research}

1. Processing and analysis of the data from scientific literature.

2. Pedagogical survey.

3. Sport-pedagogical experiment.

4. Mathematic-statistical methods

\section{Organization}

In the 2018/2019 academic year, in the training process of the basketball groups at the University of National and World Economy, a training model was tested aimed at the development of speed and strength capabilities with an emphasis on the coordination of movements in the OFP. In the preparatory stage we focused on the creation of a functional basis ensuring successful training in the various stages of the training process. We conducted a pedagogical experiment with two 
groups of female students practicing sports of their choice - basketball in physical education classes and sports at UNWE.

The subject of research is the physical development and the physical capacity of the students of economic specialties.

The object of study is the dynamics in the development of motor skills of female students at UNWE after the application of a model for the development of speed - power qualities.

A contingent of research is 38 students studying in the groups "Sports of choice - basketball" of UNWE (Sofia).

For the needs of the research the following research methods are applied: research of specialized literature; sports pedagogical testing, mathematical - statistical methods.

In order to determine the level of speed - power qualities of the participants in the experiment and the formation of equivalent for the needs of the experiment $\mathrm{EG}$ and $\mathrm{CG}$, a preliminary test was conducted. Two control and experimental groups were formed, which included students from the basketball groups of UNWE, each of 19 athletes.

\section{Content of the model in sport-pedagogical experiment}

During the whole period of the pedagogical experiment the girls from the control group worked according to the approved methodology, and those from the experimental group worked on the complexes specially created for the model aimed at developing bounce, speed and improving the rhythm and coordination of movements when performing technical - tactical techniques. The complexes included:

- Special running exercises to develop reaction speed.

- Exercises to develop reaction speed

- Exercises to develop speed, speed - strength and jumping endurance.

- Exercises for explosive force of the upper and lower limbs.

- Special exercises for agility and flair when working with a ball.

- Exercises to develop flexibility in the joints of the upper and lower limbs.

Developing speed - strength and improving speed and coordination are key factors in achieving a highly effective game by basketball players.

The work for speed - strength qualities includes the use of series with maximum short-term loads with overcoming different weights, different jumps, and combined exercises. Speed work involved the use of complexes of special running exercises and exercises to improve reaction speed. The main tool in the work for technical tactical qualities is the specific for the game special - preparatory exercises. In addition, various coordination exercises without and with a ball were included in the EG activities.

The distribution of work for qualities during the semester is shown in Table 1.

Table 1. Distribution of work for qualities for one semester

\begin{tabular}{|l|l|l|l|}
\hline Week No & focus of quality training & method & $\begin{array}{l}\text { magnitude of } \\
\text { the load }\end{array}$ \\
\hline $\mathbf{2}$ & overall endurance & long, cross running & low \\
\hline 3 & speed qualities & intervening & average \\
\hline 4 & speed and power qualities & without interruption & high \\
\hline 5 & speed endurance & $\begin{array}{l}\text { without interruption, } \\
\text { intervening }\end{array}$ & high \\
\hline 6 & strength training & variable & average \\
\hline 7 & speed & repeated & average \\
\hline 8 & speed and power qualities & continuous, intervening & really high \\
\hline 9 & coordination qualities, strength & & Average, high \\
\hline 10 & training & repeated, intervening & high \\
\hline 11 & speed endurance & repeated & high \\
\hline 12 & special speed & even & high \\
\hline 13 & speed-power and special qualities & repeated & average \\
\hline 14 & speed & repeated, intervening & high \\
\hline 15 & overall endurance & $\begin{array}{l}\text { long running with variable } \\
\text { intensity, cross running }\end{array}$ & average \\
\hline
\end{tabular}


To determine the level of OFP we conducted two tests - at the beginning and end of the experiment, using the following tests: running $20 \mathrm{~m}(\mathrm{~s})$, running $60 \mathrm{~m}$. (s), long jump $(\mathrm{cm})$, triple jump $(\mathrm{cm})$, high jump with outstretched arms $(\mathrm{cm})$.

\section{RESULTS}

Table 2 presents the results of the testing for the level of general physical fitness of the students from EG and $\mathrm{KG}$ at the beginning and end of the experiment.

During the mathematical-statistical processing of the obtained data at the beginning of the experiment no significant differences $(\mathrm{p}>0.05)$ were found in the level of the general physical fitness of the students from the two groups.

Table 2. Dynamics of the average values of the indicators for physical fitness at the beginning and the end of the pedagogical experiment

\begin{tabular}{|l|l|l|l|l|l|l|}
\hline \multirow{2}{*}{ Test } & \multicolumn{2}{|l|}{ Beginning } & \multicolumn{2}{l|}{ End } \\
\cline { 2 - 7 } & KG & EG & & KG & EG & \\
\cline { 2 - 7 } & $\mathrm{M} \pm \mathrm{m}$ & $\mathrm{M} \pm \mathrm{m}$ & $\mathrm{p}$ & $\mathrm{M} \pm \mathrm{m}$ & $\mathrm{M} \pm \mathrm{m}$ & $\mathrm{p}$ \\
\hline Running 20 m (s) & $3,65 \pm 0,23$ & $3,63 \pm 0,27$ & $>0,05$ & $3,59 \pm 0,17$ & $3,47 \pm 0,15$ & $<0,05$ \\
\hline 60m run (s) & $9,42 \pm 0,33$ & $9,43 \pm 0,17$ & $>0,05$ & $9,36 \pm 0,15$ & $9,27 \pm 0,13$ & $<0,05$ \\
\hline Long jump (cm) & $206,27 \pm 6,23$ & $204,45 \pm 6,53$ & $>0,05$ & $217,81 \pm 4,53$ & $239,21 \pm 5,11$ & $<0,05$ \\
\hline $\begin{array}{l}\text { Triple jump from a } \\
\text { place (cm) }\end{array}$ & $520,39 \pm 17,30$ & $541,05 \pm 16,15$ & $>0,05$ & $552,10 \pm 27,50$ & $578,37 \pm 24,70$ & $<0,05$ \\
\hline $\begin{array}{l}\text { High jump with } \\
\text { outstretched arms } \\
\text { (cm). }\end{array}$ & & & & & & \\
\hline
\end{tabular}

At the end of the pedagogical experiment we conducted a re-test to measure the level of general physical fitness and the growth of indicators in both groups. The results of data processing show that in the experimental group (EG) the indicators in all tests improved significantly $(\mathrm{p}<0.05)$. In the control group (CG) the results also improved, although in the tests running at $20 \mathrm{~m}$ and $60 \mathrm{~m}$ and high jump from a place with outstretched arms, the changes were not significant.

\section{CONCLUSIONS}

1. The model had a positive effect on the results of the experimental group. Speed strength training of EG students improved in the application of the experimental training model

2. The results obtained from the study update the need to include exercises and complexes with selective impact in the training process for students in the groups of sports basketball, taking into account their level of preparation and monitor the nature of the exercises on the manifestations of physical qualities - speed, endurance coordination and flexibility.

3. The obtained results can be used as guidelines for the level of readiness in planning the training process, and can also be used to carry out ongoing control over the state of physical fitness of students.

\section{REFERENCES}

1. Kasabova, L., Influence of the special physical training on the technical-tactical skills of female students from the profiled basketball groups. Book on dis. Labor, Ed. TU - Sofia, Sofia, 2019, ISBN: 978-619167-386-5, pp. 17-18.

2. Milanova, St., Ignatova, M., Study of changes in anthropometric indicators in non-sports students. Sports and Science Magazine. Book 5-6 / 2016, p.143

3. Stavrev, S., Tsvetkov, V., "Motor qualities and psychological characteristics necessary for practicing economic professions", Sport and Science, Sofia, 2011, Extraordinary issue 2. pp. 55-58 / / ISSN 1310-3393

2. Ivanov, J., The educational component. Ed. B-ins, Sofia, 2006.

3. Georgiev, Zh., Analysis of dynamics in the development of motor skills of students in the University of Forestry after the applied model for increasing physical ability. Trakia Journal of Sciences, Vol. 17, Suppl. 1, pp 668-675, 2019, Trakia University, Available online at: http://www.uni-sz.bg, ISSN 1313-7069 (print) ISSN 1313-3551 (online), doi: 10.15547 / tjs.2019 .s.01.108, pp.668-675 


\section{KASABOVA L.}

4. Peltekova, I., (2020). University basketball. UI "St. Kliment Ohridski ”, ISBN 978-95407-4897-9. PAGE. 82

5. Peltekova, I., Interpretation of the results of the test battery "SPARQ" for basketball players ". Second International Conference, "Optimization and Innovation in the Training Process", ISSN 1314-2275, Sofia, IM. "St. Kliment Ohridski ", pp. 177-184, 2010.

6. Borukova, M., (2018). "Control of sports readiness of 13-14 year old basketball players", Sofia, Car Ins, ISBN 978-954394-242-8 p. 37

7. Georgiev J., Zlatarova J., - "Analysis of the correlations between the motor qualities of students from the University of Forestry after an applied model for the development of physical capacity." Sat. "Contemporary trends in physical education and sports", November 9, 2018, pp. 101-111, ISSN 1314-2275, Sofia University "St. Kliment Ohridski ", Sofia, 2018

8. Zatsiorsky, V., Athlete's physical qualities. F\&S., Moscow, 1966.

9. St. Milanova, 2007) Pushing a cannonball. Training and coaching. NSA PRESS. S. 2007, p.48

10.St. Milanova, 2007) Pushing a cannonball. Training and coaching. NSA PRESS. S. 2007, p.77 